\title{
Marginal ulceration of the cornea
}

\author{
A. H. GHignelL, D. L. EASTY, J. R. GHeSterton, and \\ J. THOMSITT
}

Moorfields Eye Hospital, City Road Branch, London

Marginal ulceration of the cornea represents a common ophthalmic problem. DukeElder and Leigh (1965) described two main topographical types: the simple marginal ulcer, and superficial marginal keratitis, the latter being a more extensive lesion which may progress to form a ring ulcer. The simple marginal ulcer is the object of this study (Fig. I). The onset is heralded by pain and photophobia and the symptoms may closely resemble those of a foreign body. Objectively, one or more infiltrates develop in the superficial corneal stroma and loss of the overlying corneal epithelium then leads to the formation of a characteristic grey ulcer, situated in the marginal zone of the cornea and separated from the limbus by a clear corneal zone. There is an associated conjunctival reaction with hyperaemia and chemosis. The lesions usually run a course of about

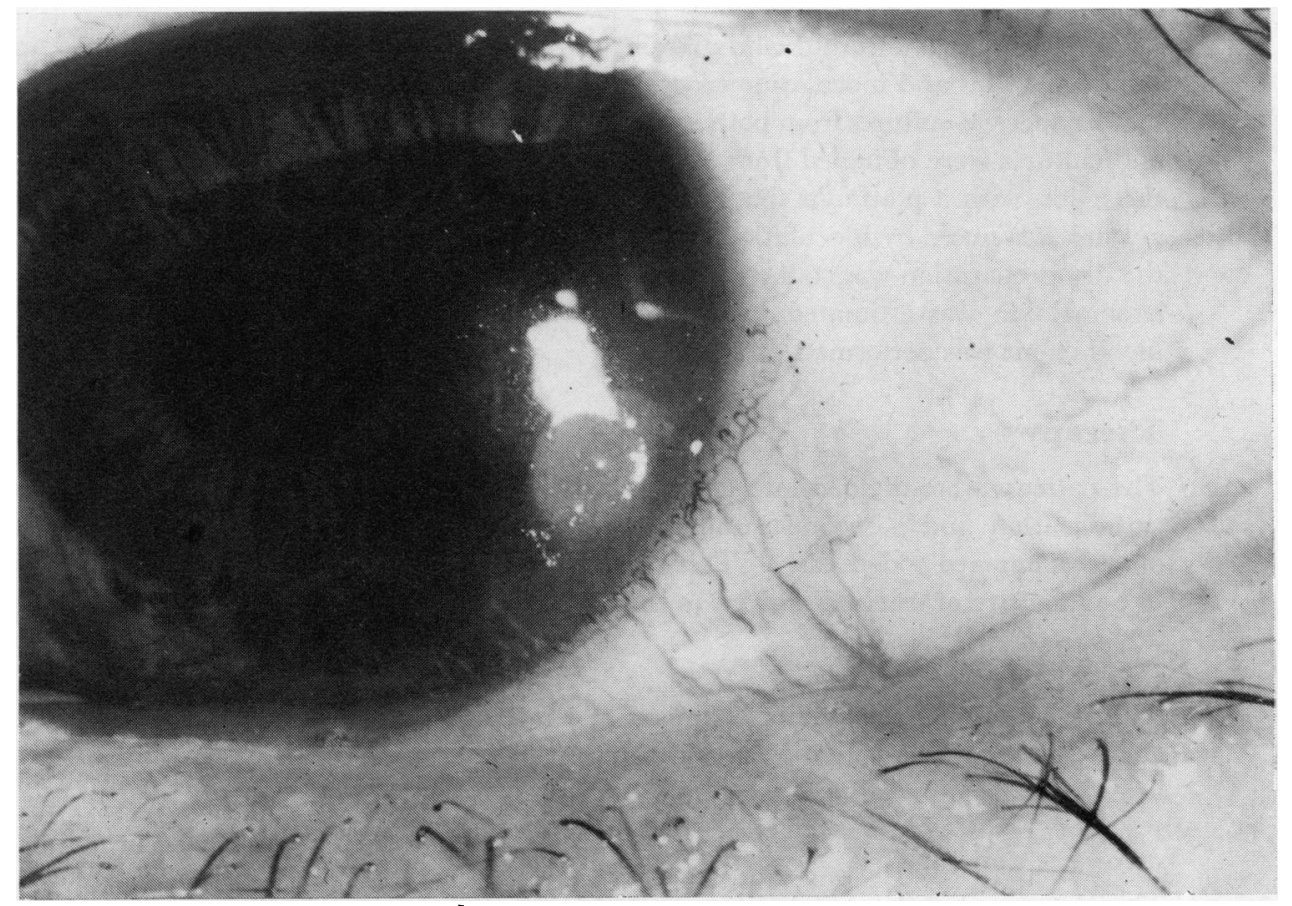

FIG. I Simple marginal ulceration of cornea 
one week, and then resolve leaving a small scar. The symptoms are commonly of sufficient severity to result in loss of time from work.

The aetiology of the condition remains rather obscure, but the strong association between the marginal ulcer and the presence of pathogenic staphylococci in the conjunctival sac and lid margins led Thygeson (1946) to believe that they resulted either from a toxic product of the staphylococcus or from a sensitivity response to its presence. Thygeson (1969) again drew attention to the association between marginal ulceration and longstanding staphylococcal blepharitis. Various methods of treatment have been advocated, e.g. carbolization, antibiotic drops, and corticosteroid drops. As yet no definitive trial of treatment has been recorded. The purpose of this study was to collect data relevant to aetiology in patients with marginal ulceration and to institute a therapeutic trial.

\section{Method}

The study was carried out on 84 patients attending Moorfields Eye Hospital, City Road, over a period of one year. Patients with direct involvement of the cornea from conjunctival disease (e.g. trachoma, rosacea) were excluded. Any patient who had already received any treatment for the present attack was not considered for the trial.

A careful history was taken from each patient, and details of age, occupation, symptoms, associated general disease, previous attacks, and precipitating factors were recorded at the initial interview. A careful examination was made of the ocular adnexa; details of lid, conjunctival, and corneal diseases were noted. The lesion itself was assessed both unstained and stained with fluorescein and its size was measured by a calibrated slit beam on a Haag Streit 900 slit lamp. Patients were seen every other day and considered to be cured when the symptoms had resolved and the corneal epithelium had healed, as shown by staining with fluorescein.

\section{Investigations}

Cultures were taken from the lid margins of both eyes, rubbing a dry cotton-tipped applicator along the lid margins and inoculating blood agar plates.

Conjunctival cultures from both inferior fornices were taken with a platinum wire loop. Scrapings and cultures were obtained from those patients who were to be treated by carbolization by scraping the lesion with a platinum spatula after the instillation of anaesthetic drops (amethocaine). The culture was made by inoculation of blood agar plates. Scrapings were placed on a glass slide and the dry preparation was stained with Giemsa and examined by light microscopy. In each case, the haemoglobin was estimated together with the erythrocyte sedimentation rate (ESR), and a full blood count was performed.

\section{Therapy}

The patients were divided into two main groups: the first 23 patients in the study were treated by carbolization and a second group of $6 \mathrm{I}$ underwent a double-blind therapeutic trial conducted on a randomized coded basis. This division was necessary because it was not possible for observers to be unaware of treatment given to the carbolization group.

GONTROLS

A third group of roo patients examined at a later date had no evidence of external ocular disease. Cultures were taken from the lids and conjunctival sacs between the months of August and December to provide a group for comparison purposes.

GROUP I (23 cases)

The ulcer was lightly carbolized under local anaesthesia; after this gutt. hyoscine 0.5 per cent. were instilled and a pad and bandage were applied for $4^{8}$ hours. 
GROUP 2 (6I cases)

In the double-blind coded series, "trial drops" only were prescribed; each patient used one of the following:

(a) Gutt. Predsol 0.25 per cent. (preserved in 0.004 per cent. phenylmercuric nitrate)

(b) Gutt. Neomycin 0.5 per cent. (preserved in 0.004 per cent. phenylmercuric nitrate)

(c) Control drops (o.004 per cent. phenylmercuric nitrate).

The allocation of drops was determined by the pharmacist by the use of random tables. In this group, no mydriatics were instilled and the eye was not bandaged, and the drops were instilled 2-hourly by day only.

The patients were seen every 2 days, and were removed from the trial if the condition was seen to be worsening or there had been no improvement in the ulcer by the end of 5 days; in accordance with standard practice in conducting a double-blind trial, neither the observers nor the patients knew the type of medication being administered.

Results (84 cases)

AGE

The age range was 18 to 75 years;

66 per cent. were between 40 and 60 years old, I 8 per cent. were less than 40 years old, I6 per cent. were more than 60 years old.

SEX

The male : female ratio was $3 \cdot 5: \mathrm{I}$.

PREVIOUS ATTACKS

39 per cent. of the patients had had at least one authenticated previous attack; an additional 20 per cent. thought they had suffered a previous attack which was not verified.

PRECIPITATING FACTOR

Io per cent. of the total gave a history of a foreign body which had entered the eye, usually a day or two before the onset of the attack. We found no case where a foreign body was actually present with a manifest marginal ulcer. A further I I per cent. gave a vague history of a foreign body being the precipitating factor.

EYE AFFECTED

In $4^{6}$ cases ( $5^{6}$ per cent.) the right eye was affected, and in $3^{8}$ cases ( 44 per cent.) the left eye.

\section{DISTRIBUTION}

The ocular distribution of the ulcers bore no obvious relationship mechanically to any associated lesion of the lid (e.g. a chalazion). The distribution is summarized in Table I (overleaf).

MORPHOLOGICAL APPEARANCES

These were characterized by the formation of single or multiple infiltrates which subsequently coalesced, and the breaking down of the overlying corneal epithelium resulted in the formation of a typical ulcer. In all our cases this ulcer was separated from the limbus by a clear area of cornea although the bloodvessels at the limbus became dilated. It was found that the character of the ulcer did not vary according to the corneal site. 
Table I Corneal distribution of marginal ulcers in 84 patients, showing quadrant involved

\begin{tabular}{|c|c|c|c|c|c|}
\hline \multirow[t]{2}{*}{ Eye } & \multicolumn{3}{|c|}{ Right (46) } & \multicolumn{2}{|l|}{ Left $\left(3^{8}\right)$} \\
\hline & Tempor & & Nasal & Temporal & Nasal \\
\hline Quadrant & $\begin{array}{l}\text { Upper } \\
\text { Lower }\end{array}$ & $\begin{array}{r}12 \\
8\end{array}$ & $\begin{array}{l}12 \\
14\end{array}$ & $\begin{array}{l}10 \\
14\end{array}$ & $\begin{array}{l}6 \\
8\end{array}$ \\
\hline
\end{tabular}

SEASONAL INGIDENGE

There did not appear to be any marked seasonal incidence; 47 cases occurred between October and March, and 37 between May and September.

GENERAL HEALTH

2 I patients had recently suffered or were currently suffering from an upper respiratory tract infection.

HAEMATOLOGY

Two patients were found to be suffering from mild iron deficiency anaemia. Three had a slightly raised ESR. These three patients were chronic bronchitics. All other haematological findings were within normal limits.

LIDS

Ten patients were considered to be suffering from infective blepharitis. A further twenty had mild squamous blepharitis. A further seven had active styes or inflamed meibomian glands.

In all the results recorded above, there was even distribution of all factors in each of the treatment groups.

CONJUNCTIVAL GULTURES

The results obtained from the whole series of 84 cases of marginal ulceration are summarized in Table II. There were 24 patients (29 per cent.) from whom Staphylococcus aureus was isolated. In twelve of these the organism was isolated from one site only, in six from two sites, in three from three sites, and in four from four sites.

Table II Distribution of organisms in 84 cases of marginal ulceration

Figures in brackets in columns represent percentage of total: some showed more than one organism

\begin{tabular}{|c|c|c|c|c|c|c|c|}
\hline \multicolumn{3}{|c|}{$\begin{array}{l}\text { Organism } \\
\text { (no. of cases) }\end{array}$} & $\begin{array}{l}\text { Staph. } \\
\text { aureus } \\
(24)\end{array}$ & $\begin{array}{l}\text { Staph. } \\
\text { albus } \\
(44)\end{array}$ & $\begin{array}{l}\text { Morax- } \\
\text { ella } \\
(4)\end{array}$ & $\begin{array}{l}\text { B. xerosis } \\
(22)\end{array}$ & \multirow{2}{*}{$\begin{array}{l}\text { Miscellaneous } \\
(2)\end{array}$} \\
\hline Site & Conjunctiva & Right & $9 \quad$ (I I ) & $22 \quad(25)$ & $2 \quad(2)$ & $12(14)$ & \\
\hline & & Left & $9 \quad(\mathrm{I} I)$ & $2 \mathrm{I} \quad(25)$ & $3 \quad(3)$ & $12 \quad(14)$ & $\begin{array}{l}\mathcal{N} . \text { catarrhalis }(\mathrm{I}) \\
\alpha \text {-haemolytic streptococci }(\mathrm{I})\end{array}$ \\
\hline & \multirow{2}{*}{$\begin{array}{l}\text { Upper and } \\
\text { lower lids }\end{array}$} & $\overline{\text { Right }}$ & $\begin{array}{ll}11 \\
\text { (12) }\end{array}$ & $32 \quad\left(3^{8}\right)$ & o & 12 (14) & o \\
\hline & & Left & $\overline{15 \quad(16)}$ & 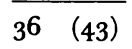 & 0 & $\overline{14 \quad(17)}$ & o \\
\hline
\end{tabular}

Table III (opposite) shows the relationship of Staph. aureus organisms to the side of the lesion. There was a greater tendency for the Staph. aureus to be obtained from either the lids or conjunctival sac on the same side as the eye affected by a marginal ulcer. 
Table III Relationship between eye affected by marginal ulceration and side from which Staph. aureus was isolated in 24 cases

Side from which Staph. aureus was isolated

$\begin{array}{lll}\frac{\text { Eye affected }}{\text { Right }} & \frac{\text { Left }}{9} & \frac{2}{3} \\ \frac{10}{3}\end{array}$

Table IV summarizes the findings from the control group of 100 patients who had no evidence of external ocular disease. In I I per cent. Staph. aureus was isolated, compared to 29 per cent. of the cases of marginal ulceration.

Table IV Percentage bacteriological distribution in 100 subjects with no evidence of external ocular disease (numbers of patients in brackets: some showed more than one organism and others showed none)

\begin{tabular}{|c|c|c|c|c|c|c|c|}
\hline \multicolumn{3}{|c|}{$\begin{array}{l}\text { Organism } \\
\text { (no. of cases) }\end{array}$} & \multirow{3}{*}{$\begin{array}{l}\text { Staph. } \\
\text { aureus } \\
\text { (I I ) } \\
0 \\
4\end{array}$} & \multirow{3}{*}{$\begin{array}{l}\text { Staph. } \\
\text { albus } \\
(67) \\
10 \\
15\end{array}$} & \multirow{3}{*}{$\begin{array}{l}\text { Morax- } \\
\text { ella } \\
(4) \\
2 \\
0\end{array}$} & \multirow{3}{*}{$\begin{array}{l}\text { B. xerosis } \\
\text { (1 } 1) \\
6 \\
7\end{array}$} & \multirow{2}{*}{$\begin{array}{l}\text { Miscellaneous } \\
(4) \\
\mathcal{N} . \text { catarrhalis }(\mathrm{I})\end{array}$} \\
\hline \multirow[t]{4}{*}{ Site } & Conjunctiva & Right & & & & & \\
\hline & & Left & & & & & $\begin{array}{l}\text { Koch-Weeks bacillus (I) } \\
\text { E. coli (I) } \\
\text { Pneumococcus (I) }\end{array}$ \\
\hline & Upper and & Right & 7 & 55 & $\mathbf{I}$ & 7 & 0 \\
\hline & & Left & 8 & 46 & I & 4 & o \\
\hline
\end{tabular}

\section{LID GULTURES}

The results are given in Table II.

CONJUNCTIVAL SGRAPINGS

In nearly all cases the results were not informative and gave no clue to the aetiology. No inclusion bodies were found and the cytology did not suggest any viral disease. Scrapings consisted mainly of epithelial cells and a few polymorphs and mononuclear cells.

\section{SGRAPINGS FROM MARGINAL ULGERS}

Material was difficult to obtain and showed only degenerate epithelial cells in most cases. There was a striking absence of cellular infiltration. No organisms were seen.

CULTURES FROM MARGINAL ULGERS

No growth was obtained from any of the 23 cases cultured.

\section{Results of Therapy}

(Table V and Figs 2, 3, 4, and 5, overleaf)

The successes and failures at the fifth day of the trial in the Predsol group were compared with the successes and failures in the control group by the $\chi^{2}$ test. It was found that there was a significant difference, the Predsol treatment being distinctly the more effective $(\mathbf{P}<$ 
Table $\mathbf{V}$ Number of patients successfully treated in each group by the fifth day of the therapeutic trial (percentages in brackets)

\begin{tabular}{|c|c|c|c|c|c|}
\hline \multirow{2}{*}{ Therapy } & \multirow{2}{*}{$\begin{array}{l}\text { Total } \\
\text { in } \\
\text { each } \\
\text { group }\end{array}$} & \multicolumn{2}{|l|}{ Resolution } & \multirow{2}{*}{$\begin{array}{l}\text { Trial } \\
\text { failures }\end{array}$} & \multirow{2}{*}{$\begin{array}{l}\text { Significance compared } \\
\text { with controls }\end{array}$} \\
\hline & & At fifth day & After fifth day & & \\
\hline Carbolization & 23 & $12 \quad(52)$ & Io $(43)$ & I （5） & $P>0.05$ \\
\hline Control & 19 & $8 \quad\left(4^{2}\right)$ & $8 \quad(42)$ & $3 \quad(16)$ & \\
\hline Neomycin & I9 & $6 \quad(32)$ & $7 \quad(36)$ & $6 \quad(32)$ & $P>0.05$ \\
\hline Predsol & 23 & $2 \mathrm{I} \quad(9 \mathrm{I})$ & $2 \quad(9)$ & 0 & $\mathrm{P}<0.001$ \\
\hline
\end{tabular}

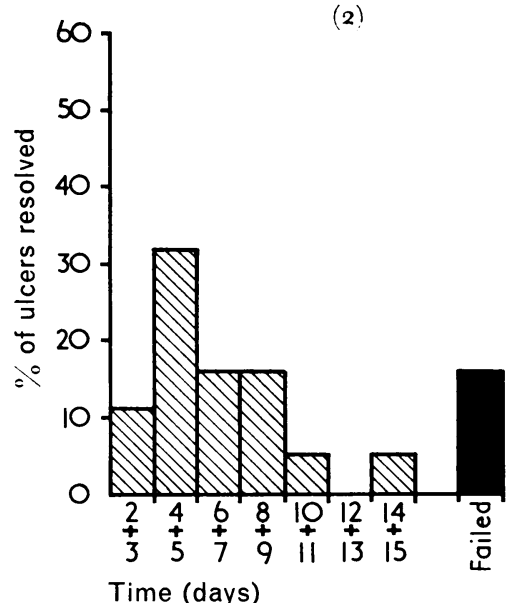

FIG. 2 Histogram demonstrating rate of resolution in nineteen patients treated with "control" drops

Each block represents the number of patients cured during 2 days

$\mathrm{F}=$ number of patients who eventually failed to respond or were becoming worse on the fifth day
(3)

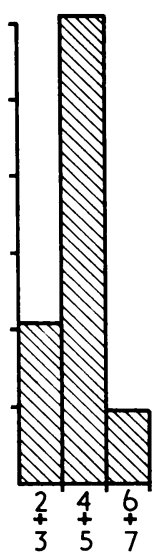

FIG. 3 Rate of resolution in 23 patients treated with Predsol drops
(4)

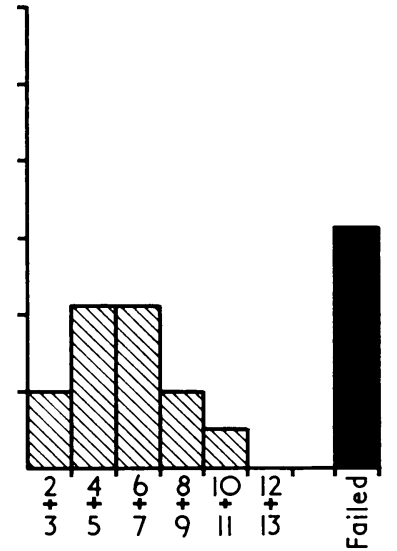

FIG. 4 Rate of resolution in nineteen patients treated with Neomycin drops

$\mathbf{F}=$ number of patients who failed to respond and were removed from the trial

o.oor). A further comparison between the control and Neomycin groups $\left(\chi^{2}=0 \cdot 4\right)$ and between the control and carbolization groups $\left(\chi^{2}=0.73\right)$ showed no significant difference. These findings indicate that, of the eyedrops used, only corticosteroid drops proved to be of benefit in the treatment of this condition.

\section{Discussion}

The aetiology and therapy of marginal ulcers have not been frequently investigated. Thygeson (1946) examined a series of patients and suggested that these ulcers are either $\stackrel{\mathbb{Q}}{\varrho}$ toxic or hypersensitive in nature. 


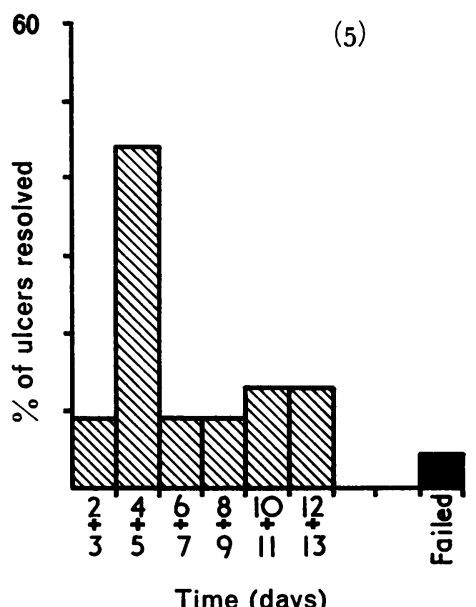

\author{
FIG. 5 Rate of resolution in 23 patients treated with \\ carbolization \\ $F=$ number of patients who failed to respond and were \\ removed from the trial
}

A high percentage of our cases occurred in patients between the ages of 40 and 60 years and it is interesting to note that no case was found in children or in very old persons. The fact that males were affected to a greater extent than females might suggest a traumatic factor in the aetiology, but the question of trauma was difficult to estimate. The symptoms of the two conditions are remarkably alike, but no foreign body was found in the presence of a marginal ulcer.

There was a considerable tendency for the lesions to recur, as is well known (39 per cent. in our series). It was considered possible that local staphylococci may provide a source of further attacks of marginal ulceration; that is, the marginal ulcer may represent a hypersensitivity or toxic response.

2 I patients (25 per cent.) had recently suffered or were currently suffering from an upper respiratory tract infection. Pathogenic staphylococci were isolated from I I per cent. of the control group, as compared to 29 per cent. of those with marginal ulceration. These bacteriological observations appear to confirm Thygeson's observations (he found pathogenic organisms in all but sixteen of his 133 cases), and it seems reasonable to assume that local pathogenic staphylococci play some part in the aetiology. A difference between the method of collection of lid margin and conjunctival cultures might account for the discrepancy in the two series. We also found that the pathogenic staphylococci are more likely to be found on the same side as the ulcer, either on the eyelids or in the conjunctival sac.

The fact that no organisms could be isolated from the lesions themselves would indicate that they are not caused by direct infection, and this is substantiated by the absence of a cellular response in the scrapings from the lesions.

In the therapeutic trial it was found that corticosteroid drops were the treatment of choice. The success of this therapy would support the theory that the lesion is a sterile inflammation, the aetiology of which is obscure. It is clear that the prompt healing induced by the administration of corticosteroid drops results in considerable economic benefit because it permits the early return to work of the patient. Vaughan (1958) mentioned that steroids may be used in treatment.

The failure of the group receiving Neomycin drops to respond also supports the belief that these lesions are not due to infection of the cornea. 
In the group of patients treated by carbolization it was necessary to instill a mydriatic and keep the eye bandaged for 2 days to prevent discomfort, and this usually resulted in a으․ loss of working days. This method has no advantage over non-surgical treatment and its use should therefore be discontinued. It should be noted that no attempt was made to suppress or eradicate the growth of pathogenic staphylococci in the lid margins by anyo medication. The possible effect of such treatment on the course of the corneal lesion or on the prevention of recurrences could well form the subject of a further study.

\section{Summary and Conclusions}

(x) An investigation is reported of the aetiology and treatment of simple marginal $\overrightarrow{\vec{\omega}}$ ulceration of the cornea in 84 patients.

(2) From the results of morphological and bacteriological studies no definite conclusionsion can be drawn concerning the aetiology. It is clear that Staphylococcus aureus plays some part in the production of a marginal ulcer (29 per cent. of cases in our study), but this organism is by no means invariably present. The mechanism by which the organismo produces a marginal ulcer is obscure, although the success of corticosteroid drops and the findings in the scrapings and cultures from the ulcers would support the theory that the ulcers might represent a hypersensitivity or toxic response to pathogenic staphylococci.

(3) In comparing the effects of carbolization, corticosteroids, or antibiotic drops with the results in controls, it was found that corticosteroid drops were highly effective in shortening the course of the ulceration, whilst both carbolization and antibiotic drops showed noß significant difference from the control group. We feel that carbolization should be discontinued as a method of treatment.

(4) Early administration of steroid drops clearly results in a more rapid resolution of symptoms and signs compared with other forms of treatment with consequent economic advantages in early return to work by the patient.

We are grateful to Prof. Barrie Jones and Mr. N. S. C. Rice for their help and encouragement in this project, $\bar{O}$ to Prof. Norman Ashton and his department at the Institute of Ophthalmology for their assistance in the investigations performed on the patients studied in the survey, and to the Department of Audio-Visual Communication of the Institute of Ophthalmology for preparing the histograms.

\section{References}

DUKE-ELDER, S., and LEIGH, A. G. (1965) "System of Ophthalmology", vol. 8, pp. 771-772.0

Kimpton, London

Thygeson, P. (1947) Trans. Amer. Acad. Ophthal. Otolaryng., 51, 198

- (1969) Amer. 7. Ophthal., 98, 446

vaUghan, D. (1958) Surv. Ophthal., 3, 203 